Article

\title{
Drone Journalism as Visual Aggregation: Toward a Critical History
}

\author{
James F. Hamilton \\ Department of Entertainment and Media Studies, University of Georgia, Athens, GA 30602, USA; E-Mail: hamilton@uga.edu
}

Submitted: 8 April 2020 | Accepted: 13 May 2020 | Published: 27 July 2020

\begin{abstract}
The use of unmanned aerial vehicles (UAVs-commonly referred to as drones) in journalism has emerged only recently, and has grown significantly. This article explores what makes drone imagery as an instance of what scholars of visual culture call an aerial view so compelling for major news organizations as to warrant such attention and investment. To do this, the concept 'visual aggregation' is introduced to theorize the authority of drone imagery in conventional journalistic practice. Imagery produced through drone journalism is a visual analogy to statistical summary and, more recently, of what is referred to as data journalism. Just as these combine an aggregate of cases to produce an understanding of an overall trend, drone imagery aggregates space visually, its broad visual field revealing large-scale spatial patterns in ways analogous to the statistical capture/analysis of large bodies of data. The article then employs a cultural and historical approach to identify key points in the emergence of visual aggregation as authoritative truth. The aerial view as a claim to truth is manifest in a wide range of antecedent social formations, devices and practices prior to their amalgamation in what has today become drone journalism. This analysis aids understanding of how drone journalism is a response to the institutional crises of journalism today.
\end{abstract}

\section{Keywords}

aerial view; drones; journalism; photography; unmanned aerial vehicles; visual aggregation; visual culture

\section{Issue}

This article is part of the issue "Journalism from Above: Drones, the Media, and the Transformation of Journalistic Practice" edited by Jonas Harvard (Mid Sweden University, Sweden), Mats Hyvönen (Uppsala University, Sweden) and Ingela Wadbring (Mid Sweden University, Sweden).

(C) 2020 by the author; licensee Cogitatio (Lisbon, Portugal). This article is licensed under a Creative Commons Attribution 4.0 International License (CC BY).

\section{Introduction}

Major news organizations have recently been diverting significant resources to develop the ability to gather imagery using unmanned aerial vehicles (UAVs), which are commonly referred to as drones. In the US alone, in 2015 ten major news companies tested drones for news-gathering (Smith, 2015). In 2016, CNN launched its CNN AIR (Aerial Imagery and Reporting) which, by the end of 2018, was staffed by close to 30 drone pilots. News organizations in the McClatchy company $(30$ companies in 14 states) included 43 licensed drone pilots on its various staffs. By the end of October 2018, a number of journalism schools in the US had incorporated drone use into their curricula, and industry training programs prepared several hundred journalists to apply for a pilot's certification (Fox, 2018; McAdams, 2016a). Major news organizations have also taken the lead in pioneering key regulations, procedures and uses in order to speed adoption of drones for journalism (Yarrish, 2018).

Given the sizable resources committed to these efforts, industry justifications are surprisingly thin. Claims about the value of drone imagery do not adequately distinguish it from other imaging technologies. After all, drone-mounted cameras are in one sense just another means of generating photographic images, which have been a staple of journalistic content for at least 100 years. Claims that drone imagery for journalistic uses "enable[s] journalists to see where they otherwise cannot and tell stories in new ways" (Fischer, 2019, p. 108), that it provides "spectacular imagery" (McAdams, 2016b), "really tell[s] the story" ("CNN drone cam," 2016), and with it "a new vantage point is reached" (Miller, 2018) can reasonably be made about a variety of remote imaging and listening devices. 
So, how might the current attention being paid to drone journalism be better understood? To start, it needs to be placed within the larger current context of interrelated, existential challenges to news organizations throughout the world. These include the partisan tabloidization of news such as efforts by News Corp to intervene in US politics, the continued decline in pubic credibility, and the hemorrhaging of revenue due to the colonization of advertising by digital giants (Gottfried et al., 2019; Pickard, 2019; Rudd, 2020).

This study contends that the development of drone journalism in the midst of perhaps the biggest institutional crisis ever in journalism is not a coincidence. Nor can drone journalism be explained as the whole-cloth and out-of-the-blue invention by a reporter or news CEO. Rather than happenstance or personal invention, this study contends that drone journalism is an emergent social and institutional means of augmenting journalistic authority during a time of unparalleled challenge. Drone journalism is a novel mode of putting into practice traditional goals of professional journalism, which are currently under siege like never before.

To substantiate this claim, this study diverges from existing work on drone journalism in a number of ways. First, in distinction with other studies that valuably address it through such problematics as surveillance (Gynnild, 2014; Herscher, 2014), this article regards drone journalism as an instance of what Dorrian and Pousin (2013) conceptualize more broadly as an 'aerial view,' which is equally the experience, social relation and representation produced through viewing imaginatively and/or actually an imagined or actual landscape while elevated in the air and looking down at it. Second, when seen in this more expansive way, the focus of interest is not simply content or meanings, but cultural practices within determinant conditions (Williams, 1980). Third, and to make clear the connection to journalism, this study conceptualizes the relevant work done by drone journalism as 'visual aggregation.' Operating through key cultural forms and formations, visual aggregation exerts an authoritative claim to truth, an accomplishment of which is essential for journalistic viability and legitimacy.

To examine visual aggregation in the necessary complexity and large scale, and encouraged by chronologically expansive works such as Adey (2010), Cosgrove and Fox (2010), and Mirzoeff (2011), this overview (pun intended) historicizes the aerial view in relation to journalism by recovering its multiple forms and placing them within their generative formations and conditions, in order to analyze the social work it does in generating claims to authority. Drone journalism is the result of numerous transformations in means of communication and the formations in and through which they were made, consisting of widely disparate areas such as theology, scouting, mapping and surveying, military planning and reconnaissance, visual-artistic genres, documentary photography, urban policing, and feature-filmmaking, all of which are sedimented and residual, yet active determinations. Key questions addressed include under what conditions have aerial views been produced? Using what means of production, and consisting of what specific kinds of features? Within what formations, and to meet what kinds of social intentions and expectations? What kinds of authority do these practices produce, and in/through what kinds of formations? How do these inform the practice of visual aggregation in journalism today? In so doing, this study places the specific case of drone imagery in journalism within the much wider intellectual project of not only a "general history of communication about space" (Harley, 1987, p. 1), but one of communicative/spatial cultural production (Couldry \& McCarthy, 2004; Harvey, 2001; Lefebvre, 1991; Shome, 2003; Soja, 1989). Counterbalancing the detail that is beyond the reach of an article-length synoptic overview is the analytic, integrative understanding it seeks to enable.

\section{Journalism, Visual Aggregation and Authority}

To understand the relevance of drone imagery for journalism, one must first establish how drone journalism assists the normative role of journalism, which is to provide authoritative accounts of events and situations in the world (Barnhurst \& Nerone, 2001). The relationship is conceptualized here as visual aggregation. How visual aggregation as a process and form furthers this normative role helps make clearer the relevance and important cultural work that drone imagery seeks to do for journalism today.

The degree to which the Western ideal of objectivity as neutral observation and description can be claimed-and thus the authority of the resulting journalistic account-depends on how well it is put into practice through a particular procedure. Informing this characteristic procedure is an epistemology best characterized as rationalist empiricism, which reached institutionalized form in early-modern England. Recalling its emergence and basis explains its nature and relevance for journalism, as well as its role in visual aggregation.

By the 17th century, the generation of authoritative knowledge was generally seen to require logical analysis, but only if paired with systematic observation of the natural world (Ash, 2004). The phrase 'rationalist empiricism' captures how Jacobean exemplar Francis Bacon and contemporaries saw as requirements for authoritative inquiry skilled, systematic deduction by naturalist philosophers, but also the testing of such knowledge in the world (Solomon, 1998, pp. 65-69). In addition to being extensive and comprehensive, the collection of data was to be done in as systematic a way as possible in order to avoid being skewed by personal preference. To do so, their collection was to be as depersonalized, routinized and mechanized as possible. In the case of 17 th century Bacon, a large team of workers followed strict, specific procedures to amass the largest amount of data possible, which then were interpreted by the project's leaders. 
As empirical data collection put another way, aggregation thus came to be institutionalized as a key component of authoritative inquiry into the natural world. Similarly, in our own day, sufficiently aggregated data are required to bolster journalism's claim to produce an authoritative account of the world. The greater extent of data that are aggregated, the greater the validity and authority of conclusions drawn due to more fully documenting broad-based processes, trends and developments.

Yet, aggregation as an epistemology and methodology is not limited to overtly scientific or journalistic inquiry. It has been done in multiple ways and to meet many kinds of social intentions. One such means of doing so that reached new levels of relevance by the 19th century was population-survey data and statistical analysis, which addressed the particular requirements of expanding national polities. Peters (2001) sees the authority of statistical aggregation as a manifestation of the emergence of modern, far-flung industrial society. Similar to other, modern forms of aggregation such as the novel (which aggregates plots) and the newspaper (which aggregates events), population statistics (which aggregates population characteristics and actions) is a "space- and time-collapsing" form of representation necessary to capture and represent such widely dispersed societies (Peters, 2001, p. 438).

The case of drone journalism suggests the necessity of much more fully recognizing the importance of visual aggregation in journalism. While aggregation in the form of a voluminous data set or documentary record is a staple topic of reporting classes, visual aggregation is largely relegated to conventional data visualization and infographics design. Yet, a more robust practice such as drone journalism seeks to aggregate spatial/geographic points and their relation. Understanding how visual aggregation via the aerial view coalesced into drone journalism today takes account of the emerging importance of spatial analysis in news and public intelligence.

\subsection{Journalism and Social Reproduction}

Due to habits of media analysis inculcated through the effects tradition, it remains tempting to analyze visual aggregation in terms of information/meanings it conveys and the cognitive/psychological effects it has. Yet, by taking the existence of the messages for granted and as the starting point of analysis, and assuming from the outset that messages and their meanings are the origin of individual and perhaps also social effects, such an approach regards attention to the social means and resources of reproduction as simply irrelevant. But, as Williams notes, this oversight shortsightedly takes for granted what it ought to explain, which is the productive forces that generate such messages and their implications. Furthermore, productive forces are not just factories staffed by wage workers, but consist in the broadest sense of "all and any of the means of the production and reproduction of real life," which includes the production of "social co-operation... [and] the application and development of a certain body of social knowledge" (Williams, 1977, p. 91).

Inquiry into the means of social reproduction of drone journalism deserves the highest level of attention, because it accounts for the relevance of visual aggregation to the current existential challenges faced by journalism as an institution. Underlying these challenges is the key problematic of how the establishment and legitimation of claims of authority in professionalized Western journalism work socially, which is a long-standing issue addressed in the US in such ways as the Lippmann and Dewey debates of the early 20th century (Dewey, 1927; Lippmann, 1922). One way that the authority of journalists' accounts is legitimized is by referencing their specialized training and knowledge. Doing so sets journalists apart from other people as a special group-what is best described as a clerisy. Compared to the less-precise term of 'elite,' clerisy specifies a restricted/protected group distinguished by a high level of learning. While, in some ways, such a basis of authority is assumed as necessary, it is also grounds for dismissal due to its isolation from the lives of a broader range of people and its undemocratic implications of a small group of people telling others what to think.

A second way that the authority of journalists' accounts is legitimized is in many ways the opposite of the first. Instead of basing it in the specialized training of a clerisy, claims of authority in this second form are validated through public deliberation, whether in the apocryphal marketplace of ideas or, as Dewey would have it, by bringing publics into being. Instead of setting them apart if not above others, this way integrates journalists and journalism into the general social process, rendering them as an aid or resource for deliberation, rather than as the source of directives. While this basis addresses the objection regarding the undemocratic implications of authority legitimized by a clerisy, it is also grounds for dismissal due to seeming to lack any basis for judging quality, accuracy or objectivity.

The problematic of claims of authority for professionalized Western journalism rest in the fact that neither of these two bases for claims of authority is sufficient in and of itself. Despite being opposites, both seem to be required. The social and institutional dimension of this problem today is in great part due to the lack of adequate means of melding, synthesizing or at least allowing both to operate. How drone journalism as visual aggregation might address this ongoing problematic is thus of primary interest and importance.

\section{Clerisy Production}

Two points need to be made regarding the earliest forms of the aerial view as relevant to drone journalism as visual aggregation. First, the aerial view existed much prior to human flight and the invention of mechanical imaging, being instead deduced through rational spec- 
ulation, and in varying degrees doctrinaire and faithbased as well as rationally-derived through mathematical proofs and limited observation of the natural world (Dixon, 2010). Second, its production and use were solely in the hands of a clerisy, which then produced the concomitant social distinctions. As will be explained, such origins and uses and their relevance to claims of authority continue to be refracted today in the claims of journalistic professionalism.

\subsection{Cosmologies}

An initial aerial view as a claim to truth took the form of a cosmology that, by merging theology and myth, aspired to nothing less than a timeless, universal account of existence. Aerial views as cosmologies have been found "in prehistoric times and [in]...nonliterate societies," and were "used as teleological instruments, epitomizing the sacred and mythical space...as well as the more tangible landscapes of the real world" (Harley, 1987, p. 4). Indeed, the presence of aerial views as cosmologies has been documented in as early as the Upper Paleolithic period (40,000 BC to about 10,000 BC; Smith, 1987, p. 55).

Instead of depicting landscapes directly observed or measured, cosmologies are typically wholly imagined 'landscapes' giving form to a mythical, foundational understanding and narrative of existence. Whether "'flat earth' cosmologies, in which the universe is seen as made up of separate layers (heaven, earth, underworld) that are in some way linked," or "spherical cosmologies of the Hindus and of Roman and medieval Europe," they share common characteristics, such as "a central or pivotal feature...such as a mountain...or the Tree of Life," or a labyrinth (Smith, 1987, p. 87). In addition, their levels or zones are "connected with the passage of the human soul after death to the afterlife or from one world to another," thus becoming as much cosmological signs as cosmological maps (Smith, 1987, p. 88).

While asserting theological doctrine, cosmologies also critiqued such doctrines, too. One of the most earthshaking transformations of early-modern European experience was brought about via the aerial view in which Copernicus challenged church doctrine with "the heliocentric system (now fully equipped with mathematical models capable of predicting planetary positions) and defended it as the true description of the universe" (Lindberg \& Numbers, 2003, p. 35).

\subsection{Scouting Reports}

Cosmologies are not the only form of pre-flight aerial view. In contrast to eternal and universal claims regarding human experience, scouting reports have the much more prosaic and tactical intention of guiding immediate and local needs of navigation, occupation and settlement.

Such reports are of particular importance for military defense and conquest, thus serving military and ad- ministrative clerisies. As such, they are an early example of the military heritage of more recent communication practices in the context of expanding empires (Aitken, 1985; Bishop \& Phillips, 2010; Williams, 1975). To operate within this military/tactical social intention, scouting reports differ from cosmologies by addressing an immediate area, and by being attuned to a particular moment, tactical situation or need. Finally, scouts who directly observe the landscape use direct speech and gesture to communicate their findings in face-to-face meetings with commanders or leaders. Indeed, direct eyewitness observation of an actual landscape is essential for establishing the authority of the observation (constituting the centrality of witnessing in journalism as the distinction of specialized knowledge).

Scouting reports' broader means of production are also quite different from cosmologies. While naturallyoccurring features such as hilltops or treetops enabled for millennia a scouting aerial view, increasingly sophisticated building and engineering techniques made possible the manufacture of manmade hills and towers on military battlements or cathedrals. Archaeological evidence of hill forts as defensive enclosures in what became the British Isles, and central and western Europe dates from the late Neolithic period (6000 BC-4000 BC), becoming more common as time went on. High ground due to the location on a natural or manufactured hill provided occupants with a strategic and defensive advantage over threats, whether human or animal (Lepage, 2012, p. 8). By 9th century England, castles located on as high an elevation as available commonly included a tower for observing the surrounding countryside (Stokstad, 2005, p. 3). Sentries in these watchtowers monitor approaching visitors from a safe distance, as well as more distant locations for signs of encampment and pillage such as columns of smoke from fires of approaching armies (Brice, 1985, p. 13). Similar to manufactured points of elevation are aids for observation. Optical aids such as telescopes extend the range and deepen the detail of what can be observed and subsequently reported.

\subsection{Surveying and Mapping}

Under pressures of colonization and empire, cosmologies and scouting reports and the work they did came to be synthesized in surveying and mapping, "a recursive social process [emphasis original] in which maps [are used to] shape a world that in turn shapes its maps [through the practice of mapping]" (as cited in Craib, 2017, p. 17). While personally-written accounts reproduce and thus more widely distribute the intelligence that had been personally gathered, the spatial-administrative needs of empire required greater scale, precision and authority. With the expansion of empires came more powerful means of rationally deriving not only a much fartherranging, comprehensive, detailed kind of scouting report but, as has been subsequently recognized by scholars, one that also makes cosmological claims about reality. 
Geometrically and mathematically generated aerial views precisely index the topographies of the natural world, accommodating them to more precise military conquest and political control as well as to land ownership (Klinghoffer, 2006). Such maps were created through surveying and the corresponding codification of schematic means of representing and thus widely distributing surveyed observations and measurements. Evidence of surveying conducted on behalf of an official land register or office exists on Sumerian clay tablets and boundary stones created at least as far back as 1000 BC (Richeson, 1966, p. 3). These maps extended the distribution of observations through time and space. When filed away in an administrative land office, maps generated through surveying extended the useful life of the observation so that, after its deposit, it could be consulted for years after.

Mapping and surveying are essential for colonization and empire. While the "connection between cartography and the exercise of imperial power is an ancient one," the "direct use of maps to further the ends of empire seems - at least at first glance-to be a modern phenomenon, closely tied to, if not dependent on, the emergence of the modern state" (Akerman, 2009, p. 1). More specifically, "not until the fifteenth and sixteenth centuries did ruling elites in Europe turn with any regularity to mapping for the management of state affairs" (Akerman, 2009, p. 1). To underscore the relationship between mapping and imperial expansion, Barrow notes that "it is no accident that the Dutch produced some of Europe's finest and most accurate maps at a time [in the 17 th century] when the country was deriving enormous profits from an expanding empire" (Barrow, 2008, p. 25).

Their means of communicative production solidified their use and relevance for an imperial, administrative clerisy. While ancient techniques of surveying requiring parsing distances using wooden rods and cords that were demarcated at specific lengths, with the measurements aggregated by using rudimentary geometric principles, the invention and use of a magnetic compass in China by the 10th century and in Europe by the 12th century was pivotal, in that "land maps could [now] be constructed by compass bearings[,] and distances could be measured from a fixed point," and at magnitudes far greater than those demarcated by a wooden rod or multiple lengths of cord (Richeson, 1966, p. 7). By the 16th century, the invention of the technique of triangulation along with the invention of the epipedometron, and aided by the application of more advanced geometry and trigonometry, made it possible to survey and thus authoritatively map "a large area, a kingdom, or a whole country" (Richeson, 1966, p. 9).

In the high precision and great informational density of schematic maps, official administrative needs were well met, while their reliance on complex mathematics along with their schematic mode of representation limits them as well to specialist, administrative uses. Along with the extensive knowledge required for how to use specialized instruments to precisely survey a land mass, specialist knowledge is also needed to decipher the surveyor's map, which are highly schematic and technical. Even early English surveyors' guide/instruction books, such as those published by William Leybourne in the 17 th century, are difficult for anyone without specialist knowledge to understand (Richeson, 1966, pp. 113-114). Diagrams reproduced in Richeson (1966, pp. 116-117) from such books that illustrate different methods of surveying appear to the untrained eye as irregular polygons, with dashed lines connecting some corners, degree measurements written in at angles, and compass headings labeling orienting lines. Author William Emerson in 1770 also notes the need for specialist training, urging that "thorough instruction should be had in arithmetic, geometry and trigonometry before the study or practice of surveying is to be done" (as cited in Richeson, 1966, p. 144).

\section{Popular Production}

Aerial views in the forms of cosmologies, scouting reports and surveyed maps are material productive practices that help reproduce their respective clerisies. This is no simple media effect, manipulation or false consciousness, but the concrete effectiveness of material cultural practices for enabling action in the world and for organizing and managing social relations (Williams, 1977). Their restriction to their respective clerisies further solidifies their claim to authority.

While conventional claims to journalistic authority rely similarly on assertions of news professionals' special training and knowledge, professional journalism in liberal polities traditionally seeks to serve its publics, not lead or govern them. Thus, claims to authority cannot simply be practices that reproduce a clerisy, but those that reproduce the formative role of readers and/or viewers as publics. Given this need, what was necessary to make visual aggregation more amenable to journalism was forms that are popularized, so as to enable the public validation of authority and claims to truth. Two points can be made about these popularizing practices in comparison to those for exclusionary clerisies. First, they validate claims to truth by using iconic instead of schematic forms of representation from sketching to cinematography, which correspond more directly and generally to individual spatial experience. Second, and to fit better the requirements of rationalist empiricism, they use increasingly mechanical means of imaging so as to be able to claim minimal skew by personal bias or preference (a contestable point as argued by Berger, Blomberg, Fox, Dibb, \& Hollis, 1973; Sontag, 1977; among others).

\subsection{Civic Promotion and Aerial Views}

Iconic aerial views are not categorically distinct from schematic, nor universally a popularizing form. For example, while ancient cosmologies were commonly iconic, not only was access to them restricted (due to the 
restricted availability and access to textual documents generally prior to the printing press and the emergence of a commercial-book trade), they were also imbued with allusions, notations and iconographic significance decipherable only by members of a clerisy possessing such knowledge (Eisenstein, 1983; Harley, 1987, pp. 2-3). Indeed, Copernicus's treatise challenging the geocentrism of the Catholic Church was hardly meant for popular reading. As Lindberg and Numbers comment: “Copernicus's book was a highly technical astronomical text, dominated by detailed geometric models for all of the planets" (Lindberg \& Numbers, 2003, p. 35).

At the same time, however, other practices of iconic representation of aerial views were developed for nonspecialist circles. A key formation developed in Europe was civic promotion in the context of Enlightenment scientific and artistic exploration of the geometries of human sight. These iconic pre-flight aerial views were not the opposite of surveys as much as enhancements and popularizations of them that sought experiential rather than mathematical accuracy. As Bury (2013) notes regarding representations of Rome that were created in the 16th century, pre-flight civic aerial views are a sketch of direct visual experience from actually existing elevated viewpoints but that are also imaginatively extended to higher points of elevation (Bury, 2013, p. 36). The result was engravings used to produce multi-panel prints for exhibition, thus requiring as much a draughtsman's as a conventional artist's skill to execute.

While based at least in part on surveys and, as such, seeking at least a degree of cartographic accuracy, preflight civic aerial views also accommodate interpretive license such as by selectively enlarging certain categories of buildings and by not depicting inhabitants (Bury, 2013, pp. 27, 34-35). As such, they were not simply flights of individual fancy or surveyed maps, but variable amalgams of both. As dal Buono writes in the early 17th century regarding his aerial view of Bologna, these were not maps but "portraits of cities [that] do not consist in their plans [schematic surveyed maps]...but in their representation exactly as the eye sees them from a determinate point of view" (as cited in Bury, 2013, p. 31). As Bury also observes about a similar case, Duperac's and Tempesta's multi-plate aerial views of Rome are not solely a personal impression, but "synthetic images packed with factual information...for the purpose of extracting detailed information about the individual buildings, streets and squares of the city" (Bury, 2013, p. 41).

\subsection{The Formation of Consumer Entertainment}

Simply on the basis of appearance, there would seem to be a direct line connecting the observed/imagined civic aerial views of dal Buono and his 17th century contemporaries, and those of 19th century Parisian Nadar as he drifted over Paris in a balloon taking photographs to be later assembled into a panoramic mosaic cityscape for public display. However, a sole focus on the formal simi- larity masks a number of key transformations that differentiate the two.

By the early 19th century in Europe and North America, of great import for the emergence of drone journalism as visual aggregation was the additional formation of popular-scientific experimentation in the context of consumer commercial entertainment, which was an industry sector already undergoing accelerating growth and expansion in the 19th century. In such a formation, the overriding social intention for visual aggregation was profitability. Aerial views worked in/through this formation by being retail experiences.

Granting the immense complexity of this historical development, two general points deserve mention as a way of making sense of their relevance for drone journalism. First is that innovations in production, distribution and exhibition continued to synthesize uses of aerial views as objective data and as personal impression/experience. Innovation in means of mechanical iconic reproduction in the 19th century further fused an experiential standard of accuracy-in which fidelity to personal visual experience (in combinations real and imagined) was the guiding standard-to the cartographic one.

Second is how the deterritorialization of aerial views in order to maximize market size also underscored the value of appeals to individual sensory experience. Popularized iconic aerial views were valued less in terms of their specific territorial referent (accuracy as judged by their fidelity with personal knowledge and experience) and more in terms of individual abstract sensory experience and pleasure. Instead of comparing the view to what one knew of the specific location to judge how accurate it was, the key comparison increasingly was whether the represented experience convincingly portrays what it would have felt like to have personally experienced it.

\subsection{Panoramas}

Panoramas as visual simulations of scenic travel engaged middle-class audiences seeking inspirational experience of iconic points of observation from around the world (Oettermann, 1997, pp. 11-12). Where circular panoramas immersed viewers by placing them at the center of a ring whose inside-facing surface was a 360-degree continuous painted image from a particular location, moving panoramas comprising sequential scenes and places scrolled a continuous journey for a seated audience (Huhtamo, 2013, p. 8). Their iconic mode made them easily understood, more fully popularized and thus more easily commodified. As a maker of horizontal panoramas (a type of merger of cartographic and iconic representation that could be reproduced in books) of peaks in the Alps observed, "while map reading is a skill that must be learned, anyone with a few years of elementary school can understand a panorama" (as cited in Oettermann, 1997, p. 37).

Panoramas in the 19th century occupied a liminal space between art and science, thus marking yet another 
point in the objective datafication of pre-photographic iconic representation. A self-aggrandizing 1862 account from the creator of a moving panorama of a journey by boat down the Mississippi River indicates as much. While being a painting, the panorama was claimed to display a "remarkable truthfulness of the minutest objects on the shores of the rivers" (Banvard, 1862, pp. 14-15). And, as Oettermann notes regarding the more schematic horizontal panoramas of the Alps (a Cubist-style composite of sketches), their makers praised such work as equally data and evocation of experience. One such alpinist/panoramist notes that "in addition to the scientific data that such correctly sketched views can provide... what pleasure can I not obtain when...I unroll [and look at] my circular drawings.....Not even the liveliest imagination can produce such an effect" (as cited in Oettermann, 1997, p. 37).

\subsection{Flight and Photography}

The key rupture that transformed aerial views was the emergence of human flight, first in balloons then by airplane, and of photography. Together they enabled the further fusion of cartographic and experiential standards of accuracy, thus providing a social means of more fully articulating the clerisy with publics. This transformation of the iconic from personal view to objective data via visual aggregation is crucial to the relevance of drone imagery for journalism.

What up to that point had only been imagined or approximated could now be directly experienced and captured mechanically, thus through eyewitnessing (a journalistic staple) and mechanical capture (a requirement of authoritative aggregation) constituting a more authoritative claim to truth. Indeed, the mechanical capture of images came to be seen in the 19th century as what Daston and Galison call "'noninterventionist' or 'mechanical' objectivity... [which is] only one of several elements that historical pressures have fused together into our current, conglomerate notion of objectivity" (Daston \& Galison, 1992, p. 82). In doing so, it also boosts the commercial value of such views, in that accuracy was and is touted as a fundamental competitive advantage. The best journalism (most read and most profitable) has conventionally been that which is the most accurate. It is this combination that today's drone journalism has developed to a high level.

Early examples of non-aerial photography underscore the extent to which the mechanically-produced iconic image was made into objective data through aggregation. One is collections by courtrooms and hospitals of individual photographic mugshots to aid police work and to authenticate passports, permits and licenses (Tagg, 1993). A second is the collection by newspaper photographer Jacob Riis of photographs of individual living conditions among immigrants living in New York City slums (Riis, 1890). Additional uses of iconic forms did the same kind of innovative cultural work. Kelsey notes regarding photographs and illustrations done for the US Geological Survey in the 19th century that the iconic and schematic were not necessarily distinct. Survey photographs exemplify a mingling of forms taken from "the map, the geologic profile, and the diagram," thus infused with "scientific exactitude, perspicacity, and detachment" (Kelsey, 1992, p. 6).

The reflections of early balloonists suggest the value of aerial photography for visual aggregation. Prince Pückler-Muskau in a balloon flight over Berlin in 1817 underscored how there was "nothing to prevent the eye from ranging over the boundless expanse" (as cited in Newhall, 1969, p. 11). Thomas Monck Mason writing in 1836 notes how "localities which he never beheld or expected to behold at one and the same view, [are now] standing side by side in friendly juxtaposition" (as cited in Newhall, 1969, p. 12). Yet, many technical limitations of early photography had to be overcome to make photography amenable to aerial views. Indeed, early imaging using daguerreotyping required not only the photographer and camera to be aloft, but an aerial darkroom complete with chemicals as well so as to process the exposures within the required time frame (Newhall, 1969, p. 19).

Some adventurous experimenters nevertheless took up the challenge of documenting the experience of human flight. The aerial-photography exploits of Parisian caricaturist/publisher-turned-photographer Nadar (née Gaspard Félix Tournachon) are perhaps the most wellknown. His conception of aerial photography illustrates the complex transition of iconic representation from personally imagined scene to mechanically transcribed data. Bann notes as much, by tracing in Nadar's written reflections a "decisive shift" from one "cognitive threshold" to another-from art to science, from impression to transcription, from image to data in which aerial photography was "a new, precise mode of seeing, capable of being harnessed to further technical tasks" (Bann, 2013, p. 86). A story that appears in Le Monde Illustré in 1858 notes that, prior to photography, where "we have had bird'seye views seen by the mind's eye imperfectly; now we will have nothing less than the tracings of nature herself, reflected on the plate" (as cited in Newhall, 1969, p. 20).

Further technical innovations in photography enabled its popularization, which expanded access from well-heeled experimenters and adventurers, to key institutions and members of the lay public. The invention in 1871 of gelatino-bromide dry plate photography substantially lengthened the time between exposure and processing, thus obviating the need to travel aloft with an aerial darkroom. Due to being more than 60 times more sensitive than wet collodion plates, it also substantially decreased the exposure time needed (Newhall, 1969, p. 34). Continued experimentation resulted in film on a roll instead of separate plates, which further reduced camera size, while the development of mechanical shutters increased precision of exposure and thus image sharpness still further (Newhall, 1969, p. 35). The result of these and other such innovations was that photogra- 
phy came to be "so greatly simplified that almost anyone could take photographs anywhere with no more trouble than pressing a button," meaning that "balloon photography, once a tour de force of the professional, now became common" (Newhall, 1969, p. 36).

Along with its popularization came its relevance for clerisy uses, too, such as military reconnaissance for tactical planning as well as for damage assessment (Kaplan, 2006; Mead, 1983; Oxlee, 1997). Systems for strapping and operating cameras from airplanes pioneered in the early 20th century came to be crucial by WWI, with the enhancement of imagery produced through melding a succession of overlapped images into stereoscopic form (Newhall, 1969, pp. 52-53).

\subsection{Cinematic Aerial Views}

By the late 19th century, photographic images in popular as well as clerisy formations had come to constitute through aggregation objective visual data. The final piece needed to complete the pre-conditions for drone journalism was not only that of cinema but a cinematic syntax and language, plus their social acceptance and understanding along with public systems and institutions for their production, distribution and exhibition. In doing so, the static iconic view-as-data provided by balloon and later airplane photography could be superseded through commercial visual entertainment and its development, distribution and exhibition of dynamic, iconic visual experience-as-data.

At the start of cinema, the actors moved, but the camera did not. Commonly, a single stationary camera on a tripod captured action that took place in front of it, with the viewpoint thus produced analogous to that of a single seated spectator in an audience watching a play on a theater stage. When used in aerial views, this tableau approach to visual narrative de-emphasized the experiential while emphasizing the objective, such as in its early predominant use in documentary newsreels (Castro, 2013, pp. 123, 127). Aerial views such as these were "eminently instrumental and functional," with practitioners informed that such footage "is good in terms of their documentary quality, such as visibility, topography and reconnaissance capacity" (Castro, 2013, p. 123). As Castro concludes, "indexical images obtained from the air [came to be regarded as]...the natural replacement for cartographic images" (Castro, 2013, p. 123).

A fusion of experiential with objective-and thus a better fit with the requirements of commercial journalism, which must engage as well as inform-required innovations in cinematic editing, which reconfigured this static and unengaging visual approach. Not only do moving images correspond more fully to personal visualsensory experience by unfolding through time, through the innovation of editing they produce a modernist fragmentation of experience that visually aggregates by producing a supra-individual spatial experience. Marked by the work of major early filmmakers Griffith and
Eisenstein, and analogous to expansive panoramic novels of Tolstoy, Dickens and many others, multi-camera filmmaking interlaced scenes and plots to depict what no single person in continuous experience could directly apprehend. With such innovations, spectators themselves while viewing through the camera now moved as did actors. Production and editing innovations allowed cinema to not just mimic the experience of an eyewitness to a single, continuous action, but produce a personal experience of time/space/viewpoint mobility and a paradoxically fragmented/aggregated visual narrative.

While camera movement in the earliest years of cinematic experimentation can be seen in the work of the Lumière brothers, its sophistication proceeded rapidly (Castro, 2013, p. 125). Cameras on dollies (platforms with wheels that move on a set of tracks) could follow actors and action in a panoramic way. But of greater import to cinematic aerial views was the innovation of vertical moving shots and their narrative significance. Booms allowed an operator on the ground to film as the camera attached to one end was levered into the air or returned to earth from an elevated position. Crane shots raised the camera and operator even higher into the air. When booms or cranes were also mounted on dollies, the technical means were in place to create sweeping aerial movement vertically as well as horizontally, which is a signature shot employed in drone journalism. Early innovative examples include a variety of boom and crane shots on dollies in Intolerance (Griffith, 1916), and a variety of shots of and from airplanes in Wings (Hubbard \& Wellman, 1927).

\section{Drone Journalism in Retrospect}

Concluding this study with the development of aerial scenes in early 20th century scripted silent feature films may seem to be a curious choice, particularly in view of a host of subsequent technological innovations in imaging and sensing, flight and control, visual aggregation and analysis, as well as the emergence of additional relevant activating formations, including journalism and its use of drone imagery for visual aggregation. Journalistic uses range from overviews of protests, demonstrations and other large gatherings of people, to forays into dangerous areas ravaged either by natural disaster or military incursion. Treading the ground of early cinema, drone journalism has only recently begun to embrace multicamera editing in lieu of single-camera continuous-shot segments. Doubtless additional uses will emerge.

Yet, doing so meets the goal of establishing how visual aggregation exerts an authoritative claim to truth, the accomplishment of which is essential for journalistic viability and legitimacy. Drone journalism's claim to truth is produced not solely by journalistic uses, but contextually and historically by the still active weight of sedimented practices and formations of aerial viewing.

What is most important, then, to recognize regarding the current industry effort to develop drone journalism is 
not simply the footage taken, but how drone journalism works socially to claim authority which, for journalism in liberal polities, is both exceptionally important and exceptionally difficult. The challenge is to adequately synthesize a contradiction, both poles of which are necessary: the restriction of production to a clerisy (to validate specialist professional training, but which also produces the problem of elitism and thus social division), and the involvement of publics (to validate what ideally is meant to be the integrative, organic role of journalism to the publics it serves, but which also encourages the problem of tabloidization and the abandonment of professionalism in order to secure commercial success). This crux of the social problem of journalism is embodied in a particularly graphic way by drone journalism. It remains to be seen whether drone journalism will be able to sufficiently address it.

\section{Acknowledgments}

Gratefully acknowledged are the critical readings of two anonymous reviewers, and the collaboration and intellectual innovation at 'Journalism From Above: Drones and the Media in Critical Perspective,' an international workshop that took place at Mid Sweden University, Sundsvall 18-20 September 2019 that was organized/hosted by Jonas Harvard, Ingela Wadbring, Mats Hyvönen, and Terje Lindblom, and at which an early version of this research was presented.

\section{Conflict of Interests}

The author declares no conflict of interests.

\section{References}

Adey, P. (2010). Aerial life: Spaces, mobilities, affects. Chichester: Wiley-Blackwell.

Aitken, H. (1985). The continuous wave: Technology and American radio, 1900-1932. Princeton, NJ: Princeton University Press.

Akerman, J. R. (2009). Introduction. In J. R. Akerman (Ed.), The imperial map: Cartography and the mastery of empire (pp. 1-9). Chicago, IL: University of Chicago Press.

Ash, E. H. (2004). Power, knowledge, and expertise in Elizabethan England. Baltimore, MD: Johns Hopkins University Press.

Bann, S. (2013). Nadar's aerial view. In M. Dorrian \& F. Pousin (Eds.), Seeing from above: The aerial view in visual culture (pp. 83-94). London: I. B. Tauris.

Banvard, J. (1862). Description of Banvard's geographical painting of the Mississippi River. New York, NY: L. H. Biglow.

Barnhurst, K., \& Nerone, J. (2001). The form of news: A history. New York, NY: Guilford.

Barrow, I. J. (2008). Surveying and mapping in colonial Sri Lanka. New Delhi: Oxford University Press.
Berger, J., Blomberg, S., Fox, C., Dibb, M., \& Hollis, R. (1973). Ways of seeing. London: Penguin.

Bishop, R., \& Phillips, J. (2010). Modernist avant-garde aesthetics and contemporary military technology: Technicities of perception. Edinburgh: Edinburgh University Press.

Brice, M. (1985). Stronghold: A history of military architecture. New York, NY: Schocken.

Bury, M. (2013). The meaning of Roman maps: Etienne Dupérac and Antonio Tempesta. In M. Dorrian \& F. Pousin (Eds.), Seeing from above: The aerial view in visual culture (pp. 26-45). London: I. B. Tauris.

Castro, T. (2013). Aerial views and cinematism. In M. Dorrian \& F. Pousin (Eds.), Seeing from above: The aerial view in visual culture (pp. 118-133). London: I. B. Tauris.

CNN drone cam shows devastation in Louisiana. (2016, August 18). CNN. Retrieved from https://www.cnn. com/videos/weather/2016/08/18/louisianaflooding-cnn-drone-footage-vo-earlystartreader.cnn

Cosgrove, D., \& Fox, W. L. (2010). Photography and flight. London: Reaktion.

Couldry, N., \& McCarthy, A. (Eds.). (2004). MediaSpace: Place, scale and culture in a media age. London: Routledge.

Craib, R. B. (2017). Cartography and decolonization. In J. R. Akerman (Ed.), Decolonizing the map: Cartography from colony to nation (pp. 11-71). Chicago, IL: University of Chicago Press.

Daston, L., \& Galison, P. (1992). The image of objectivity. Representations, 40, 81-128.

Dewey, J. (1927). The public and its problems. New York, NY: Henry Holt.

Dixon, T. (2010). Introduction. In T. Dixon, G. Cantor, \& S. Pumfrey (Eds.), Science and religion: New historical perspectives (pp. 1-19). Cambridge: Cambridge University Press.

Dorrian, M., \& Pousin, F. (Eds.). (2013). Seeing from above: The aerial view in visual culture. London: I. B. Tauris.

Eisenstein, E. L. (1983). The printing revolution in early modern Europe. New York, NY: Cambridge University Press.

Fischer, D. A. (2019). Don't stop me now: Prioritizing drone journalism in commercial drone regulation. Columbia Journal of Law \& the Arts, 43(1), 107-146.

Fox, T. (2018, October 9). Drone journalism's battle for airspace. Columbia Journalism Review. Retrieved from https://www.cjr.org/innovations/drones-faajournalists-airspace.php

Gottfried, J., Stocking, G., Grieco, E., Walker, M., Khuzam, M., \& Mitchell, A. (2019). Trusting the news media in the Trump era. Pew Research Center. Retrieved from https://www.journalism.org/2019/12/ 12/trusting-the-news-media-in-the-trump-era

Griffith, D. W. (Producer, Director). (1916). Intoler- 
ance [Motion picture]. USA: Triangle Distributing Corporation.

Gynnild, A. (2014). The robot eye-witness. Digital Journalism 2(3), 334-343.

Harley, J. B. (1987). 1: The map and the development of the history of cartography. In J. B. Harley \& D. Woodward (Eds.), The history of cartography: Cartography in prehistoric, ancient, and medieval Europe and the Mediterranean (Vol. 1, pp. 1-42). Chicago, IL: University of Chicago Press.

Harvey, D. (2001). Spaces of capital: Towards a critical geography. New York, NY: Routledge.

Herscher, A. (2014). Surveillant witnessing: Satellite imagery and the visual politics of human rights. Public Culture, 26(3), 469-500.

Hubbard, L. (Producer), \& Wellman, W. A. (Director). (1927). Wings [Motion Picture]. USA: Paramount Pictures.

Huhtamo, E. (2013). Illusions in motion: Media archaeology of the moving panorama and related spectacles. Cambridge, MA: MIT Press.

Kaplan, C. (2006). Mobility and war: The cosmic view of US "air power." Environment and Planning A, 38(2), 395-407.

Kelsey, R. (1992). Archive style: Photographs and illustrations for U.S. surveys, 1850-1890. Berkeley, CA: University of California Press.

Klinghoffer, A. J. (2006). The power of projections: How maps reflect global politics and history. Westport, CT: Greenwood.

Lefebvre, H. (1991). The production of space (D. NicholsonSmith, Trans.). Cambridge: Basil Blackwell.

Lepage, J.-D. (2012). British fortifications through the reign of Richard III. Jefferson, IA: McFarland.

Lindberg, D. C., \& Numbers, R. L. (2003). When Christianity and science meet. Chicago, IL: University of Chicago Press.

Lippmann, W. (1922). Public opinion. New York, NY: Harcourt, Brace and Co.

McAdams, D. (2016a, August 18). CNN creates drone unit. TVTechnology. Retrieved from https://www. tvtechnology.com/news/cnn-creates-drone-unit

McAdams, D. (2016b, August 30). CNN AIR: Q\&A with Greg Agvent. TVTechnology. Retrieved from https://www.tvtechnology.com/news/cnn-air-qawith-greg-agvent

Mead, P. (1983). The eye in the air: History of air observation and reconnaissance for the Army, 1785-1945. London: Her Majesty's Stationary Office.

Miller, J. (2018). About. Unequal Scenes. Retrieved from https://unequalscenes.com/about

Mirzoeff, N. (2011). The right to look: A counterhistory of visuality. Durham, NC: Duke University Press.

Newhall, B. (1969). Airborne camera: The world from the air and outer space. New York, NY: Hastings House.

Oettermann, S. (1997). The panorama: History of a mass medium. New York, NY: Urzone.

Oxlee, G. J. (1997). Aerospace reconnaissance. London:
Brassey's.

Peters, J. (2001). "The only proper scale of representation": The politics of statistics and stories. Political Communication, 18(4), 433-449.

Pickard, V. (2019). Democracy without journalism? Confronting the misinformation society. New York, NY: Oxford University Press.

Richeson, A. W. (1966). English land measuring to 1800: Instruments and practices. Cambridge, MA: MIT Press.

Riis, J. (1890). How the other half lives: Studies among the tenements of New York. New York, NY: Scribner's.

Rudd, K. (2020, May 7). The Murdoch media's China coronavirus conspiracy has one aim: Get Trump reelected. The Guardian. Retrieved from https://www. theguardian.com/media/2020/may/08/murdochmedia-china-coronavirus-conspiracy-trump-kevinrudd

Shome, R. (2003). Space matters: The power and practice of space. Communication Theory, 13(1), 39-56.

Smith, C. D. (1987). 4: Cartography in the prehistoric period in the Old World: Europe, the Middle East, and North Africa. In J. B. Harley \& D. Woodward (Eds.), The history of cartography: Cartography in prehistoric, ancient, and medieval Europe and the Mediterranean (Vol. 1, pp. 54-101). Chicago, IL: University of Chicago Press.

Smith, G. (2015, January 16). Ten news outlets to test drones for journalism. SUASNews. Retrieved from https://www.suasnews.com/2015/01/ten-newsoutlets-to-test-drones-for-journalism

Soja, E. W. (1989). Postmodern geographies: The reassertion of space in critical social theory. New York, NY: Verso.

Solomon, J. R. (1998). Objectivity in the making: Francis Bacon and the politics of inquiry. Baltimore, MD: Johns Hopkins University Press.

Sontag, S. (1977). On photography. New York, NY: Farrar, Straus \& Giroux.

Stokstad, M. (2005). Medieval castles. Westport, CT: Greenwood.

Tagg, J. (1993). The burden of representation: Essays on photographies and histories. Minneapolis, MN: University of Minnesota Press.

Williams, R. (1975). Television; technology and cultural form. New York, NY: Schocken.

Williams, R. (1977). Productive forces. In R. Williams (Ed.), Marxism and literature (pp. 91-94). Oxford: Oxford University Press.

Williams, R. (1980). Base and superstructure in Marxist cultural theory. In R. Williams (Ed.), Problems in materialism and culture (pp. 31-49). London: Verso.

Yarrish, G. (2018, January 30). Drones in the news: Six ways major news organizations are pushing the drone industry forward. Rotor Drone Pro. Retrieved from https://www.rotordronepro.com/drones-news6-ways-major-news-organizations-pushing-droneindustry-forward 


\section{About the Author}

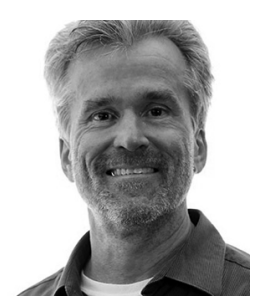

James F. Hamilton is the Jim Kennedy Professor of New Media, Head of the Department of Entertainment and Media Studies, and Director of the New Media Institute at the University of Georgia, US. His research concerns democratic communications, alternative media and communication technologies. Among his published work is Democratic Communications: Formations, Projects, Possibilities (2009), Alternative Journalism (2009, co-written with Chris Atton), and an edited volume with Robert Bodle and Ezequiel Korin, Explorations in Critical Studies of Advertising (2017). 